\title{
Chronic health effects of sulphur mustard exposure with special reference to Iranian veterans
}

\author{
M Balali-Mood ${ }^{1}$, SH Mousavi ${ }^{1}$, and B Balali-Mood ${ }^{2}$ \\ ${ }^{1}$ Medical Toxicology Research Centre and Department of Medicine, Imam Reza Hospital, Mashhad University of Medical Sciences, Mashhad, \\ Iran; and ${ }^{2}$ Department of Chemistry, Imperial College London, London, UK.
}

\section{Correspondence}

Professor M Balali-Mood, Medical

Toxicology Centre, Imam Reza Hospital Medical School, Mashhad University of Medical Sciences, Mashhad 91735-348, Iran. E-mail:

mbalalimood@hotmail.com

Received 6 February 2007 Revised 20 February 2008 Accepted 3 March 2008

\begin{abstract}
The widespread use of sulphur mustard (SM) as an incapacitating chemical warfare agent in the past century has proved its long-lasting toxic effects. It may also be used as a chemical terrorist agent. Therefore, all health professionals should have sufficient knowledge and be prepared for any such chemical attack. SM exerts direct toxic effects on the eyes, skin, and respiratory tissue, with subsequent systemic action on the nervous, immunological, haematological, digestive, and reproductive systems. SM is an alkylating agent that affects DNA synthesis, and, thus, delayed complications have been seen since the First World War. Cases of malignancies in the target organs, particularly in haematopoietic, respiratory, and digestive systems, have been reported. Important delayed respiratory complications include chronic bronchitis, bronchiectasis, frequent bronchopneumonia, and pulmonary fibrosis, all of which tend to deteriorate with time. Severe dry skin, delayed keratitis, and reduction of natural killer cells with subsequent increased risk of infections and malignancies are also among the most distressing long-term consequences of SM intoxication. However, despite a lot of research over the past decades on Iranian veterans, there are still major gaps in the SM literature. Immunological and neurological dysfunction, as well as the relationship between SM exposure and mutagenicity, carcinogenicity, and teratogenicity are important fields that require further studies, particularly on Iranian veterans with chronic health effects of SM poisoning. There is also a paucity of information on the medical management of acute and delayed toxic effects of SM poisoning - a subject that greatly challenges health care specialists.
\end{abstract}

\section{History \\ Synthesis}

Sulphur mustard (SM) or mustard gas is bis(2-chloroethyl) sulphide and was first synthesised in 1822 by Despretz. Its vesicant properties were noted by Guthrie in $1860 .{ }^{1}$ In 1886 , Victor Meyer was the first to prepare pure SM by the reaction of thiodiglycol with phosphorus trichloride. Thiodiglycol was prepared by the reaction of 2-chloroethanol with potassium sulphide. Thiodiglycol can also be prepared by the American process, in which ethylene oxide reacts with hydrogen sulphide. SM was produced for use as a chemical warfare agent (CWA) by what is known as the Leveinstein process: the reaction of ethylene with sulphur dichloride before the First World War (WWI). ${ }^{2}$

\section{Applications}

SM has been the most widely used CWA in the past century. It was employed extensively in the WWI between 1914 and 1918. In spite of the Geneva Protocol in 1925 on the prohibition of CWA, SM was used by Italian troops in Ethiopia (1935-1936) and by Egyptian forces in Yemen (1963-1967). Recently, the greatest use of SM was by the Iraqi Army against Iranian soldiers and even civilians in Sardasht and Halabjah between 1983 and 1988, resulting in over 100,000 chemical casualties. ${ }^{3}$

Although there have been no substantiated reports of the use of SM by terrorist groups, the simplicity of its chemical synthesis does offer the potential for use by terrorists.

\section{Type of exposure}

Single

Most human cases of SM poisoning have occurred during armed conflicts and most accidents were a single exposure. ${ }^{4}$

\section{Multiple}

Multiple, low, SM exposure occurred occupationally and during the WWI and in the Iran-Iraq conflict. ${ }^{4,5}$ 


\section{Secondary}

First-aid workers, nursing, and medical staff who were looking after SM casualties in the field clinics and hospitals during the Iraq-Iran war without proper personal physical protection have become intoxicated. Some of them are now suffering from the delayed toxic effects of SM and have disabilities of between 5 and $25 \% .^{6}$

Sub-clinical

Sub-clinical exposure to SM in some Iranian combatants induced delayed toxic effects. A study on 77 subjects, who were present in a contaminated area and had no acute symptoms or signs at the time of exposure, are now suffering from respiratory disorders such as bronchiectasis and bronchiolitis obliterans. $^{7}$

\section{Chronic}

Chronic SM exposure is usually occupational. Some factory workers in Japan and in the UK were reported to have had SM poisoning and even malignancies due to SM., ${ }^{8,9}$

\section{Routes of exposure}

\section{Inhalation}

Inhalation is the major route of exposure that induces respiratory and systemic toxicity following absorption across the lung surface. ${ }^{10}$

\section{Dermal}

$\mathrm{SM}$ is a vesicant or blistering agent that has direct toxic effects on the skin producing erythema, blistering, epidermolysis, and necrosis. It is a lipid-soluble compound and thus can be readily absorbed across the skin. ${ }^{2,11}$

\section{Ocular}

The eyes are the most sensitive organs to SM. This marked susceptibility is attributable to several ocular features including the aqueous-mucous surface of the cornea and conjunctiva, as well as the high turnover rate and intense metabolic activity of the corneal epithelial cells. ${ }^{5,12,13}$

\section{Oral}

SM may also enter the body by oral ingestion. We observed a few Iranian combatants during the war who had ingested food contaminated by SM and who subsequently became intoxicated. They experienced nausea, vomiting, haematemesis, abdominal pain, and dyspnoea. SM may also be absorbed through the lower gastrointestinal tract. ${ }^{14}$

\section{Injections}

Injection is a very rare route of SM intoxication and has not been reported.

\section{Toxicity}

Supra-acute

Exposure to very high doses of SM in the field may induce convulsions and death in less than $1 \mathrm{~h} .{ }^{15,16}$ Such observations have not been reported during the Iraq-Iran war.

Acute

Acute toxic effects generally appear after variable periods of latency depending on the dose, mode of exposure, the environmental temperature, and probably on the individual. ${ }^{2,17,18}$

Sub-acute

Sub-acute exposure occurred during the Iran-Iraq war and in the workers in the SM munitions factories. However, this type of exposure may present as a mild, acute SM intoxication or as a complication in the respiratory tract or even as malignancy. ${ }^{6}$

\section{Delayed}

Delayed toxic effects of SM have been documented. The first report of delayed toxic effects in Iranian veterans was reported in $1986 .{ }^{19}$ Several articles on the delayed toxic effects and complications of SM in Iranian veterans have been published since. ${ }^{6,7,10,11,13}$

\section{Chronic}

Several studies suggest that workers who were chemically exposed to mustard agents in the British and Japanese munitions factories developed chronic respiratory effects. In a cohort mortality study of 3500 workers at a manufacturing plant in England, a statistically significant increase in the number of deaths due to influenza, pneumonia, bronchitis, and asthma were reported. This was present even among those with fewer than 3 years of employment at the plant and so was not related to the duration of employment. ${ }^{20}$

A 25-year follow-up study of workers exposed to SM in a Japanese production plant revealed that more highly exposed workers had more chronic bronchitis and a slightly lower forced expiratory volume in one second/forced vital capacity (FEV1/FVC) ratio than either the less-exposed or an unexposed group of their co-workers. ${ }^{9}$ In another study, Brown ${ }^{8}$ reported a large number of employees who worked at the Huntsville Arsenal in Alabama. They were continuously exposed to the gas over long periods of time and developed bronchiectasis with progressive emphysema and narrow attenuated bronchioles. ${ }^{8}$ Cancer of the respiratory system has also been associated with occupational exposure to SM and is discussed later in this article.

\section{Toxicodynamics}

Monofunctional mustards have one alkylating site and therefore can attack and break the DNA at specific nucleotides. Although SM reacts with RNA, proteins, and phospholipids, the consensus view is that a DNA alkylate, plays an important role in delayed toxic effects. ${ }^{21,22}$ The major alkylating site of nucleic acids of mammalian origin is the nitrogen residue of guanine. ${ }^{23}$ Cell death from DNA cross-linking is delayed until the cell replicates its DNA or undergoes division. At higher 
cellular exposures, however, mechanisms other than DNA cross-linking become important and produce more rapid cell death. The acute damage to the cornea, mucous membranes, and skin seen after SM exposure is probably generated by one or more of these other mechanisms. One mechanism that may be involved in acute damage is nicotinamide adenine dinucleotide (NAD) depletion. Other potential mechanisms of cell death are related to rapid inactivation of sulphydrylcontaining proteins and peptides, such as glutathione. These sulphydryl compounds are critical in maintaining the appropriate oxidation-reduction state of cellular components. Glutathione is also thought to be critical in reducing reactive oxygen species in the cell and preventing peroxidation and loss of membrane integrity. ${ }^{24,25}$

\section{Toxicokinetics}

SM is absorbed by inhalation, through the skin, or through the anterior surface of the eye. It may also be absorbed through the gastrointestinal tract following consumption of contaminated food. When delivered as liquid or vapour, the skin plays a very important role as a port of entry for SM. SM undergoes hydrolysis producing half-mustard and thiodiglycol, which is the major metabolite and is excreted in urine.

From the total mustard that penetrates, only $10-20 \%$ is fixed to macromolecules in skin. The remaining $80-90 \%$ is rapidly transported away from the site of absorption by the circulation. ${ }^{26-28}$ In terminally ill cancer patients, $80-90 \%$ of the radioactivity of the injected ${ }^{14} \mathrm{C}$-labelled SM disappeared after several minutes from the blood and was excreted mainly in the urine within $24 \mathrm{~h}^{29} \mathrm{SM}$ is eliminated in a two-compartment model. The distribution of SM is quick with a long terminal half-life $(5.56 \mathrm{~min}$ and $3.59 \mathrm{~h})$. The volume of distribution at steady state $\left(V_{\mathrm{dss}}\right)$ is $74.41 .^{30}$ Whole body autographic studies with ${ }^{35}$ S-labelled SM have shown that elevated radioactivity was detected in the nasal region, followed by the kidneys, liver, and intestines at all times studied after percutaneous or intravenous administration. ${ }^{31}$ In humans, unhydrolysed SM can be present in brain and fat depots days after exposure. ${ }^{32}$ Few data are available on biotransformation of SM in man. Two studies in rats revealed that conjugation with glutathione is more important than hydrolysis. ${ }^{29,33}$ More recent investigations demonstrated that $60 \%$ of the dose is excreted within $24 \mathrm{~h}$ in the urine. ${ }^{30}$

\section{Mutagenicity}

There is no evidence for the mutagenicity of SM and no evidence of teratogenicity was found in rats treated with different doses of SM. ${ }^{17,34}$

\section{Carcinogenicity}

SM is classified as a carcinogen by the International Agency for Cancer Research. Human studies indicated a causal association between occupational exposure to SM and the excessive occurrence of respiratory cancer, skin cancer, and, possibly, leukaemia. ${ }^{35}$ A significant excess of deaths (33 cases against 0.9 expected) due to respiratory cancer was found among former workers of the Japanese poison gas factory that operated from 1929 to $1945 .^{36}$ Similarly, highly significant excesses in cancer of the larynx, pharynx, and other upper respiratory sites were observed in former employees of a British plant that manufactured SM. A moderate, but still significantly higher mortality than normal population was also observed in lung cancer. ${ }^{37}$ Gastric cancer, basal cell carcinoma, Bowen's disease, Bowen's carcinoma, and skin spinocellulare have all been reported following occupational exposure to mustard gas. $^{20,38,39}$

\section{Effects on reproductive system}

A few studies are available regarding the reproductive effects of SM. Intravenous injection of SM in male mice results in damage to the testes, with inhibition of spermatogenesis. ${ }^{40}$ Nevertheless, the damage is usually transient, because testicular recovery is observed at two weeks, with the formation of mature sperms four weeks after exposure. A two-generation study of rats indicated that exposure to SM at levels of $0.03,0.1$, and $0.4 \mathrm{mg} / \mathrm{kg} / \mathrm{day}$ did not have any adverse effects on reproductive performance or the fertility of male or female rats throughout two consecutive generations, except for an altered sex ratio in the $0.4-\mathrm{mg} / \mathrm{kg}$ group. ${ }^{34}$

\section{Target organs}

Eyes

Eyes are the most sensitive organs to SM. The first symptoms of SM exposure are usually those on the eyes. ${ }^{5,12,13}$

\section{Respiratory tract}

Next to the eye lesions, the greatest discomfort produced by mustard gas results from irritation and toxicity of the respiratory system. Respiratory effects occur in a dosedependent manner from the nasal mucosa to the terminal bronchioles ${ }^{5,10,41}$

\section{Dermis}

Direct toxic effects of SM on the skin are the main apparent effects that lead to it being called a vesicant or blistering agent. A German medical toxicologist and an Iranian medical toxicologist (first author) classified the cutaneous mustard gas lesions as follows:

- erythematous form;

- pigmentary exfoliation;

- superficial vesicular to bullous form;

- bullous necrotisation;

- deep necrotising non-bullous form; and

- allergic and toxic contact reactions of the skin.

Different forms of the above cutaneous lesions may be observed in one patient. The pigmentary exfoliative form is often combined with severe lung damage. ${ }^{42}$ 
Gastrointestinal tract

Gastrointestinal effects after SM exposure have been documented in some studies. Destruction of the mucosa and shedding of the epithelial elements, however, begin days after exposure, resulting in loss of large volumes of fluid and electrolytes. ${ }^{40,43}$ Acute gastroduodenitis with haemorrhagic erosions, acute desquamative enteritis, and severe haemorrhagic necrotic colitis were reported in the WWI veterans ${ }^{44}$ but not observed in the Iranian veterans.

\section{Central nervous system}

Extremely heavy exposure to SM can cause central nervous system (CNS) excitation leading to convulsions in animals. ${ }^{15}$ Balali-Mood and Navaeian ${ }^{19}$ reported convulsions in six Iranian veterans who were hospitalised during the early stages of their intoxication. Most casualties from the WWI and from the Iran-Iraq conflict, however, revealed mild and very non-specific neurological effects such as headache, anxiety, fear of the future, restlessness, confusion, and lethargy. ${ }^{19}$

\section{Peripheral nervous system}

A frequent long-term complication in patients exposed to SM is delayed neuropathic symptoms, which are underrepresented in most previous studies. ${ }^{45}$

\section{Haematopoietic system}

As an alkylating agent, SM is particularly toxic to rapidly proliferating cells such as lymphoid and bone marrow cells. Leukocytosis is common within the first few days after exposure. White blood cell counts then begin to drop on the third and fourth days after exposure and reach their minimum level around the ninth day. This leukopaenia is followed by a decrease in megakaryocytes and finally in the erythropoietic series. ${ }^{46-49}$ Bone marrow biopsies have shown hypocellular marrow and atrophy involving all elements. ${ }^{14}$ If cytopaenia is not marked and there are still remaining stem cells, recovery will take place as the patient recovers. ${ }^{15}$ The bone marrow studies reveal a severe decrease in cellularity and fat replacement, and nuclear changes, such as budding, double nuclear, and kariorrhexis in erythrocyte precursors. The toxic effects of SM on the haematopoietic system are dose dependent, and it is concluded that SM causes aplastic or ineffective haematopoiesis. ${ }^{50}$ Severe leukopaenia, however, is an ominous sign, leading to secondary infections and higher mortality rates in these patients. SM victims with white blood cell counts of 200 cells/ml or less died during their initial admissions. ${ }^{46}$ Aplastic anaemia in seven patients with SM poisoning six to 12 months after exposure was also reported. ${ }^{2}$

\section{Immune system}

SM poisoning can result in the impairment of both humoral and cellular immune functions. ${ }^{46,49,51}$ Along with the appearance of clinical disorders, both C3 and C4 titres showed an increase, followed by a gradual decrease over one year. The majority of SM-exposed patients had increased levels of immunoglobulin (Ig)-G and IgM during the first weeks and up to the sixth month after exposure. ${ }^{52}$

Depression of cell-mediated immunity has been observed in the Iranian veterans one, two, and three years after exposure. ${ }^{53}$ Natural killer cells, which are known to be one of the most important components of the cellular immunity, have been found to be significantly lower in patients with severe respiratory complications 10 years after exposure. ${ }^{54}$ In a controlled study, the number of natural killer cells was still significantly lower 16-20 years after exposure. ${ }^{6,49}$

\section{Endocrine system}

SM may affect several different target organs comprising the endocrine system. The total and free testosterone levels were markedly decreased in the first 5 weeks after SM exposure, but all returned to normal by the twelfth week after exposure. A significant diminished sperm count in 77 SM veterans three to nine years after exposure have been reported. ${ }^{34}$ Another study showed that $66 \%$ of 42 men examined one to three years after SM exposure had sperm counts of less than 3 million cells $/ \mathrm{ml}$ and their folliclestimulating hormone levels were higher than normal men. ${ }^{2}$

\section{Clinical effects \\ Acute}

The first contact with SM is usually painless and only a garlic or sulphur odour can be noticed. Normally, a symptom-free interval is observed for several hours. The duration of this interval correlates inversely with the absorbed dose of the agent. Eyes, skin, and the respiratory system are the three major targets for the local toxic effects of SM.

Initial clinical symptoms and signs occur in the eyes about onehour after exposure, starting with a sensation of grittiness, a progressive soreness, and a bloodshot appearance, proceeding to acute conjunctivitis. After several hours, the corneal epithelium begins to vesicate and slough, leading to severe pain, blepharospasm, and decreased visual acuity. Gradual spontaneous recovery usually occurs after 48 hours, with full regeneration of the corneal epithelium within four to five days. Complete symptomatic recovery, however, may take six weeks or longer. ${ }^{5,12,13,16}$ Skin effects commence with erythema a few hours after exposure with no itching or pain leading to blister formation and further lesions within hours and days later as mentioned above. ${ }^{52}$

Respiratory symptoms usually occur earlier than skin lesion with dyspnoea, coughing, and chest discomfort progressing to acute rhinopharingo tracheobronchitis. In severe cases, bronchopneumonia, adult respiratory distress syndrome, and even pulmonary emboli may develop causing mortality mostly in the second week after exposure. $5,14,16$

The symptoms of systemic poisoning are very similar to those caused by radio- or chemotherapy. Low-dose exposure may result in headache, nausea, vomiting, and loss of appetite. Higher dose exposure may damage more severely the gastrointestinal tract and the bone marrow. This may 
result in immune suppression, leukopaenia, diarrhoea, fever, weakness, and, in very severe cases, excitation of the CNS with convulsions. ${ }^{2,55}$ The maximum intensity of symptoms can be reached after days. An exposure to large doses of SM can cause damage to the haematopoietic and the immune system. ${ }^{49,50}$

\section{Delayed}

During the Iran-Iraq war, about 100,000 people suffered from SM exposure and now after 20 years, around 40,000 veterans have complained of delayed effects. ${ }^{4,6,56}$ The first report of delayed toxic effects in Iranian veterans was reported in 1986 as mentioned above. ${ }^{19}$ The most prominent late clinical effects were observed in the respiratory tract (78\%), neuropsychiatrics systems (45\%), skin (41\%), and eyes (36\%). ${ }^{19,38}$

\section{Chronic}

Chronic occupational exposure to SM is discussed above. The majority of clinical symptoms and signs were observed in the respiratory tract, presenting as coughing with or without productions, dyspnoea, wheezing, and bronchial rale. Chronic bronchitis, obstructive, and restrictive lung diseases leading to chronic obstructive pulmonary disease and bronchiectasis have been reported. ${ }^{6}$ Malignancies, particularly in the respiratory tract and haematopoietic system, may occur.

\section{Complications}

It is very difficult to differentiate between the delayed toxic effects and complications of SM poisoning. However, complications may be defined as the persistent, permanent, and life-threatening delayed toxic effects of SM. Long-term complications of SM are discussed below.

\section{Identification}

\section{Environmental}

Environmental identification of SM in the field is of great medical importance to confirm the diagnosis, and to evaluate and decontaminate those exposed. Decontamination of the environment also requires agent identification.

\section{Air}

Identification of SM in the air is now possible using portable detectors, special biosensors that are available in some advanced chemical defence laboratories. It is also possible to quantify SM concentration in the air using a portable gas chromatograph-mass spectrometer. ${ }^{57}$

Soil

SM is a very stable compound and has been identified in the soil many months, and even years, after exposure under particularly cold environmental conditions. SM and its hydrolysis products including half-mustard and thiodiglycol can be identified and quantified by the specific and sensitive analytical methods such as gas chromatography-mass spectrometry (GC-MS). ${ }^{58}$
Water

$\mathrm{SM}$ is insoluble in water and its hydrolysis in the environment is very slow. However, identification of SM in water is possible in advanced environmental and CBRN defence laboratories by GC-MS. ${ }^{57}$

\section{Patients}

Alkylation products of SM with DNA and proteins (for example, haemoglobin and albumin), as well as its urinary metabolites, have been proven to be useful targets for the diagnosis of SM exposure in humans. Urinary markers are readily accessible, although their rapid elimination limits their use for retrospective detection. Adducts with macromolecules such as proteins offer longer lasting biological markers for exposure to SM, possibly up to several months. ${ }^{59}$

\section{Blood}

The primary site of DNA alkylation by SM is the N7 position of deoxyguanosine residues. ${ }^{60}$ Upon depurination of the resulting N7-(2-hydroxyethylthioethyl)-0-2'-deoxyguanosine, N7-(2-hydroxyethylthioethyl) guanine (N7-HETE-Gua) is obtained. Although GC-MS analysis has proved problematic, N7-HETE-Gua can be conveniently analysed using liquid chromatography-mass spectrometry. ${ }^{61}$ The adduct can be detected in urine, and also after processing of skin and blood samples of animals exposed to SM. An enzymelinked immunosorbent assay (ELISA) has been successfully developed using monoclonal antibodies raised against N7HETE-guanosine-5'-phosphate coupled to keyhole limpet haemocyanin. ${ }^{62}$

This method was applied to blood samples from two casualties of the Iran-Iraq War, collected 22 and 26 days following the alleged exposure to SM. ${ }^{63}$ The alkylation of proteins by SM mainly occurs in carboxyl, amino, and sulphydryl groups, as well as in the nitrogens of the imidazole ring of histidine. Definitive evidence of specific alkylation sites can be obtained by using modern mass spectrometric (MS) techniques. Although MS methods can be used to confirm the diagnosis under more sophisticated conditions, the ELISA approach has been mainly developed for use under field conditions. Haemoglobin and albumin are two abundant proteins in human blood that can be readily isolated for the determination of SM adducts. $^{2,59}$

\section{Urine}

Although the hydrolysis product of SM, namely thiodiglycol, is only a minor metabolite, the sulphoxide derivative of thiodiglycol is abundantly present in the urine and can be reduced to thiodiglycol for GC-MS analysis. ${ }^{63}$

Unfortunately, both thiodiglycol and its sulphoxide, are not unequivocal markers of poisoning in humans, and low concentrations are present in normal human urine. ${ }^{64-67}$ The -lyase metabolites, which are derived from an initial reaction of SM with glutathione, are unequivocal biomarkers 
and can be reduced to thioether derivatives for subsequent GC-MS analysis. ${ }^{68}$ This method has been applied to urine samples from two human casualties accidentally exposed to the agent and from five Iranian casualties of CW attacks. The -lyase metabolites were detected in one sample collected 13 days after the alleged SM exposure. ${ }^{68,69}$

\section{Blister fluid}

Analysis of the vesicle fluid for thiodiglycol may confirm a suspected SM exposure. The fluid contained in the vesicles is not toxic and presents no risk to the attending medical staff. $^{70}$

Tissue

The DNA adduct can also be detected in skin of human exposed as it was done after processing in animals exposed to SM. ${ }^{62}$ Organ tissues of the post-mortem samples taken from chemical Iranian martyrs revealed SM with different concentrations in different organs. ${ }^{31,32}$

\section{Post mortem}

Toxicological analyses of the post-mortem samples (blood, urine, and organ tissues) of two Iranian chemical gassed combatants who died in Belgian hospitals, revealed SM. ${ }^{32}$ The detailed biological fate of SM in Iranian chemical poisoned patients who were hospitalised in British hospitals including post-mortem toxicological analyses reported. ${ }^{71}$

\section{Ethical considerations}

All studies performed by the authors in this review followed the standard ethics. They were all confirmed by the University Medical Research Ethics Committee and were carried out after written informed consent of the patients was obtained. Figure 2 is from a patient whose consent for publication has been obtained.

\section{Long-term complications}

Information on the long-term effects of SM comes from two major lines of investigations: studies of soldiers who were exposed to the agent on the battlefield, and studies of workers who were employed in mustard gas factories (occupational exposure). Although long-term effects after battlefield exposure are referred to as 'late' or 'delayed' complications, the term 'chronic' is more suitable for the complications caused by occupational exposure. It must also be emphasised that delayed effects generally occur some months or years after a single or brief exposure and are not the same as chronic poisoning, which comes from continuous intake of the poison over a relatively long period of time. The first report on the delayed toxic effects of SM poisoning in 236 Iranian veterans revealed that the most common effects were on the respiratory tract (78\%), CNS $(45 \%)$, skin $(41 \%)$, and the eyes (36\%). These effects were recorded between two and 28 months after exposure. ${ }^{21}$ Comparison of early (one week after exposure) and late (2 years after exposure) toxic effects of SM poisoning in 77 CWA

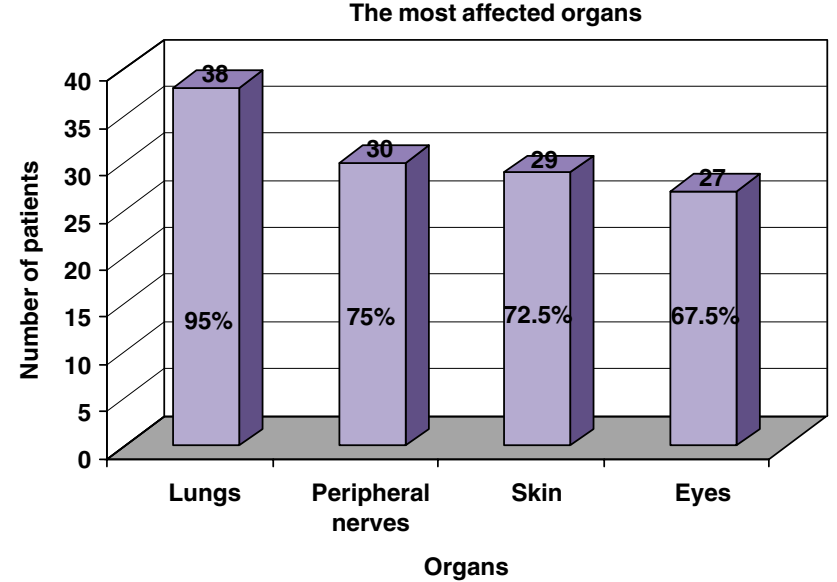

Figure 1 Frequency of delayed complications of SM in different organs of 40 Iranian veterans in Mashhad.

victims indicated that eye lesions do not change significantly, dermal complications tend to decrease, and respiratory complications generally deteriorate over the years. ${ }^{72}$ In a study on 34,000 Iranians, 13-20 years after exposure to SM, the most common complications were found in the lungs (42.5\%), the eyes (39\%), and the skin $(24.5 \%) .{ }^{23}$ In a group of 40 severely intoxicated Iranian veterans in Mashhad, 16-20 years after their initial exposure, the most commonly affected organs were lungs (95\%), peripheral nerves (77.5\%), skin (75\%), and eyes (65\%) as shown in Figure 1.

\section{Respiratory}

Respiratory problems are the greatest cause of long-term disability among people with combat exposure to mustard gas. A triad of cough, expectoration, and dyspnoea has been found to be present in more than $80 \%$ of Iranian veterans three years after their initial exposure. ${ }^{24}$ Haemoptysis (mainly streaky), chest tightness, chest pain, and nocturnal dyspnoea are also frequent. The main objective clinical findings are generalised wheezing (the most common sign), crackles, decreased lung sounds, clubbing, and cyanosis. ${ }^{6,25}$

Pulmonary function testing has revealed more obstructive patterns than restriction and about half of these obstructive spirometric results are reversible in response to inhaled bronchodilators. FVC, FEV1, and FEV1/FVC (FEV1\%) have all been found to be significantly lower in SM-intoxicated veterans compared with healthy unexposed individuals and CWA survivors who had used a gas mask at the time of attack. $^{24}$ Abnormal spirometric findings, in general, and restrictive patterns, in particular, tend to increase over time. ${ }^{2,19,73}$ A study on 77 subjects, who were present in a contaminated area and had no acute signs and symptoms at the time of exposure, but now have respiratory disorders, indicates that sub-clinical exposure to SM can be responsible for the occurrence of delayed respiratory complications such 
as bronchiectasis and bronchiolitis obliterans. ${ }^{7}$ Chest radiograph findings in patients with late respiratory complications of SM have been described as increased bronchovascular markings, hyperinflation, bronchiectasis, pneumonic infiltration, and radiological evidence of pulmonary hypertension. ${ }^{19,74}$ However, chest radiographs are not sensitive enough for the detection of respiratory complications in these patients and high-resolution computed tomography of the chest may be required as the diagnostic imaging procedure of choice. ${ }^{75}$ A study of 197 Iranian veterans 10 years after a single heavy exposure to SM revealed the development of a series of delayed destructive pulmonary sequelae such as chronic bronchitis (58\%), asthma (10\%), bronchiectasis (8\%), large airway narrowing $(9 \%)$, and pulmonary fibrosis $(12 \%){ }^{71}$

\section{Chronic bronchitis}

Several studies have reported chronic bronchitis as the most common late complication of the respiratory system resulting from war exposure to mustard gas. ${ }^{7,76,77}$ Hypoxaemia and hypercapnoea are commonly observed in moderate to severe cases, leading to cor pulmonale and respiratory failure in the final stages of the disease. ${ }^{78,79}$ Infection of the respiratory tract, resulting in bronchopneumonia, is also a common problem, often complicated by septicaemia. ${ }^{80}$

\section{Asthma}

Airway hypersensitivity, manifested as typical attacks of breathlessness, wheezing, and nocturnal cough, as well as a reversible obstructive pattern on pulmonary function tests, have been reported between four weeks to 20 years after SM inhalation. Patients with chronic bronchitis may also have some degree of bronchospasm, which does not respond to bronchodilators. Attacks of bronchospasm are characteristically triggered by respiratory infections, environmental allergens, and cold weather. ${ }^{77,78}$

\section{Bronchiectasis}

Direct effects of SM on the bronchial wall mucosa and, more recurrent, respiratory infections following SM inhalations are known to be responsible for the development of bronchiectasis. Both the severity and frequency of bronchiectatic lesions tend to increase over the long-term followups, as evidenced by a study of 40 Iranian veterans with severe late complications of SM poisoning. These lesions usually begin bilaterally in the lower lobes and then progress towards the middle lobe and the lingula. In severe cases with extensive bronchiectatic lesions, pulmonary hypertension, and ultimately cor pulmonale may occur. ${ }^{7,78,81}$

\section{Large airway narrowing}

Airway narrowing, due to scarring or granulation tissue, is a late sequel of acute injuries to the trachea and large bronchi, usually developing two years after exposure. ${ }^{6,82,83}$ A study of 19 Iranian veterans with large airway narrowing due to SM, revealed stenosis in the trachea (seven patients), main bronchi (eight patients), and lobar bronchi (four patients). ${ }^{77}$ In contrast to stenosis caused by prolonged intubations, there is no predilection in the right main bronchus. ${ }^{78,82}$ The major problem in these patients is the recurrence of the lesion, which usually occurs 6 months after treatment. ${ }^{83}$

\section{Pulmonary fibrosis}

Late-onset pulmonary fibrosis has been reported in several Iranian veterans with combat exposure to $\mathrm{SM} .^{77,78}$ The analysis of bronchoalveolar lavage fluid from patients with mustard gas inhalation showed that these patients have an ongoing local inflammatory process of the lower respiratory tract resulting in the development of pulmonary fibrosis years after the initial exposure. Histopathological examination of transbronchial lung biopsies (TBLBs) of SM-exposed veterans revealed variegated fibrosis, diffuse fibrosis, and an absence of fibrosis in 86,4 , and $10 \%$ of the patients, respectively. Usual interstitial pneumonitis accounted for $97 \%$ of all cases of fibrosis. ${ }^{84}$ In another study, electron microscopic examination of seven TBLB specimens was carried out in a WHO research centre in Japan. Abnormal findings included proliferation, desquamation, and degeneration of the bronchial epithelial cells; interstitial fibrosis or fibrosing alveolitis; and an increased type I and type II alveolar epithelial cells as well as hyperplasia of ciliated and goblet cells. ${ }^{85}$ Inflammation and fibrotic processes in the lung tissue of SM-exposed patients may be progressive. ${ }^{56}$ Diffusing capacity of the lung could be used as an objective monitor of the degree of fibrosis and also as a good predictor of prognosis. $^{77}$

\section{Dermal}

The occurrence and persistence of lesions following SM exposure is directly related to the duration and severity of exposure. Injury that results in erythema and oedema without vesicle formation is almost always followed by a complete healing and no residual effects. ${ }^{2,86}$ Blistering and necrotic wounds, however, cause permanent residual effects. The first report of delayed toxic effects of SM poisoning two years after exposure, in 236 Iranian veterans, revealed late skin effects such as hyperpigmentation (34\%), hypopigmentation (16\%), and dermal scarring (8\%). ${ }^{19}$ The most common skin complaint among these patients was itching followed by a burning sensation and desquamation. These symptoms are basically owing to dryness of the skin and thus become worse in dry weather and after physical activity. A more recent study of 40 Iranian veterans, who were heavily exposed to the gas 16-20 years previously, revealed the most common cutaneous lesions as hyperpigmentation, erythematous papular rash, dry skin, multiple cherry angiomas, atrophy, hypopigmentation, and hypertrophy. These lesions were found on the genital areas (48\%), the back (48\%), the front thorax and abdomen (44\%), the lower extremities (mainly inguinal) (44\%), the upper extremities (mainly auxiliary) (41\%), and the head and neck (15\%). Dry skin was more prominent in the extremities. Hyperpigmentation 
in some patients had the appearance of pigmented xerodermoid, which is a diffuse hyperpigmented area with superimposed macular hypo- and hyperpigmentations. ${ }^{6,11}$

In another study, the cutaneous lesions of 500 SM-exposed Iranian veterans were compared with that of 500 unexposed veterans. An association was found between SM exposure and late skin lesions such as severe dry skin, hyper- and hypopigmentation, local hair loss, eczema, and chronic urticaria. There was also a higher incidence of vitiligo, psoriasis, and discoid lupus erythematosus among SMpoisoned patients. This could be due to the immunological basis of these disorders and the fact that SM has adverse longterm effects on the immune system. Previously injured sites have been reported to be sensitive to subsequent mechanical injury and showed recurrent blistering after mild injury. ${ }^{87}$

Histopathological examination of skin biopsies has revealed non-specific findings including epidermal atrophy, keratosis, and basal membrane hyperpigmentation. Nonspecific fibrosis and melanophages have also been observed within the dermis. ${ }^{6,11,78,87}$ Areas (head and neck) of hyperand hypopigmentations of a patient two years after SM exposure are shown in Figure 2. Occupational exposure to SM has been demonstrated to cause a variety of skin changes, including pigmentary disorders, skin ulcers, and cutaneous cancers. $^{88}$

\section{Ophthalmological}

In less than $1 \%$ of patients with battlefield exposure to SM, a delayed type of ulcerative keratopathy may develop, leading to late-onset blindness. ${ }^{89-92}$ The maximum delayed toxic effects usually occur 15-20 years after initial exposure, although latency periods as long as 40 years or as short as six years have also been reported. ${ }^{13,93,94}$ Patients are usually symptom free for an indefinite number of years when delayed keratitis develops, characterised by photophobia, lacrimation, and failing vision. ${ }^{92}$

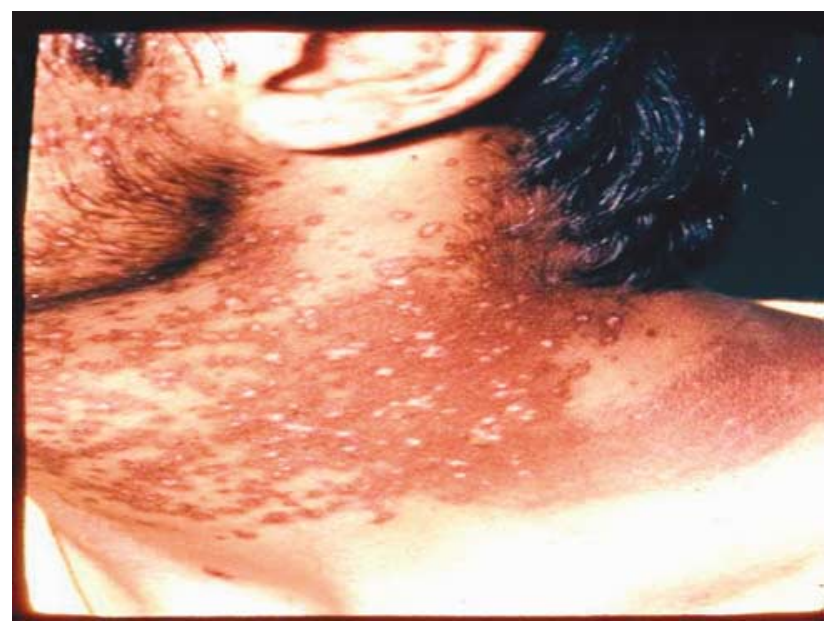

Figure 2 Hyperpigmentation of the blister sites in an Iranian veteran with delayed complication of SM.
In acute stages, the limbal region frequently presents a marbled appearance in which porcelain-like areas of ischaemia are surrounded by blood vessels of irregular diameter. Later, vascularised scars of the cornea are covered with crystal and cholesterol deposits, leading to a worsening of the opacification, recurrent ulcerations, and sometimes, corneal perforation. Opacification of the cornea is seen predominantly in the lower and central portions, whereas the upper part is often protected by the eyelid. ${ }^{92,94}$ Surprisingly, lesions even recur after corneal transplantation. ${ }^{93}$ The exact pathogenesis of this condition is unknown, but degenerative processes and immune reactions against corneal proteins (collagen-mustard compound) have been suggested as the cause of long-term damage. ${ }^{94}$ Unfortunately, there has been no report on any long-term studies on mustard gas workers to determine their ocular status after prolonged occupational exposure.

\section{Neuropsychiatric conditions}

Casualties from WWI and from Iran-Iraq conflict were noted to have long-term mood and anxiety disorders, as well as post-traumatic stress disorder. ${ }^{95,96}$ Debility, loss of vitality, impaired concentration, sensory hypersensitivity, diminished libido, weakened potency, neuralgic complaints, and disorders in autonomic regulation are the common manifestations. Neuropsychiatric evaluation of 1428 Iranian veterans, three to nine years after exposure to SM, revealed anxiety (15\%), depression (46\%), personality disorders (31\%), convulsions (6\%), and psychosis (3\%). ${ }^{38}$ Disorders of consciousness (27\%), attention (54\%), emotion (98\%), behaviour (80\%), thought process (14\%), and memory (80\%) were studied in 70 patients, three to five years after SM exposure. ${ }^{97}$ Depression and post-traumatic stress in Iranian survivors of chemical warfare, mostly SM exposure, were also reported. ${ }^{98}$ In another study, decreased libido and impotence were recorded in 52 and $9 \%$ of the patients, respectively. Interestingly, $10 \%$ of the patients revealed an increased libido. Functional photophobia, functional aphonia, and effort syndrome have also been reported. ${ }^{6}$

\section{Neuromuscular conditions}

Electromyography (EMG) and nerve conduction velocity $(\mathrm{NCV})$, on 40 Iranian veterans with severe late manifestations of SM poisoning, revealed abnormalities in the peripheral nervous system of $77.5 \%$ of the patients. NCV disturbances were more common in sensory nerves compared with motor nerves and more prevalent in the lower extremities than in the upper extremities. EMG recordings revealed a normal pattern in $24(60 \%)$ patients, incomplete interference with normal amplitude in six (15\%) patients, and incomplete interference with low amplitude in 10 (25\%) patients. NCV and EMG disturbances in both upper and lower extremities were mostly symmetric. ${ }^{78}$

Immunological and haematopoietic myelosuppression is the most serious effect of SM. SM can cause long-term effects on the immune system in patients with severe intoxication. 
Table 1 Significant changes of haematological and immunological parameters in 40 patients with severe SM intoxication compared to 25 normal individuals

\begin{tabular}{lccl}
\hline & Patient mean \pm s.d. & Control mean \pm s.d. & P-value \\
\hline WBC $\left(1000 / \mathrm{mm}^{3}\right)$ & $7.24 \pm 1.90$ & $5.79 \pm 1.12$ & 0.025 \\
RBC $\left(\right.$ million $\left./ \mathrm{mm}^{3}\right)$ & $5.46 \pm 0.45$ & $5.19 \pm 0.28$ & 0.035 \\
Monocyte $(\%)$ & $4.8 \pm 1.6$ & $3.9 \pm 1.1$ & 0.013 \\
HCT $(\%)$ & $48.3 \pm 3.5$ & $45.5 \pm 1.9$ & 0.047 \\
lgM $(\mathrm{mg} / \mathrm{dl})$ & $235.3 \pm 84.8$ & $136.8 \pm 58.3$ & 0.0001 \\
C3 MIC $(\mathrm{g} / \mathrm{dl})$ & $109.8 \pm 30.1$ & $90.9 \pm 14.8$ & 0.03 \\
CD3 $(\%)$ & $71.1 \pm 8.6$ & $65.6 \pm 10.7$ & 0.037 \\
CD16+5 (NK cells) & $11.6 \pm 5.8$ & $17.5 \pm 9.6$ & 0.006 \\
\hline
\end{tabular}

Abbreviations: HCT, haematocrit; Ig, immunoglobulin; MIC, minimum inhibitory concentration; NK, natural killer; RBC, red blood cell; SM, sulphur mustard; WBC, white blood cell.

The impaired immunity is probably responsible for the increased risk of infections in these patients. Forty male subjects (aged $43.8 \pm 9.8$ years), who had confirmed SM poisoning 16-20 years before the study, were investigated. Significant changes of haematological and immunological parameters in these patients compared with 25 normal individuals are summarised in Table $1 .{ }^{49}$

\section{Mutagenicity}

A two-generation study of rats indicated that mustard gas was not teratogenic. ${ }^{17,34}$ There has been no other report on the teratogenicity of SM and no clear evidence of this problem following human exposure, although there have been some claims made.

\section{Carcinogenicity}

SM is genotoxic because of its reactions with DNA, which is an important first step in carcinogenesis. Although most cells possess effective DNA repair mechanisms, these are not always effective in the case of SM damage. Alkylation of $\mathrm{O}_{6}$-guanine by $\mathrm{SM}$ seems to be critical. $\mathrm{O}_{6}$-ethylthioethylguanine is a poor substrate for the DNA repair enzyme $\mathrm{O}_{6}$-alkylguanine-DNA alkyltransferase. ${ }^{99}$ Therefore, this $\mathrm{O}_{6}$-lesion may be the most important mutagenic lesion. However, only limited data are available on the specific mutations produced by SM. Mutations in a tumour suppressor or an oncogene gene can favour a proliferate advantage of a clonal cell. Notably, alterations in the p53 tumour suppressor gene have been described in Japanese mustard gas workers. $^{100}$

However, most of the lesions in this population were similar to smoking-related mutations. Mutations in lymphocytes at the hypoxanthine phosphoribosyltransferase (hprt) gene locus have also been reported. ${ }^{101}$

\section{Reproductive}

The effects of SM exposure during pregnancy are unknown. Data addressing the productive toxicities of SM in human models are both lacking and contradictory. ${ }^{102}$

\section{Management}

Specific

No specific antidote has been developed for the treatment of $\mathrm{SM}$. Sodium thiosulphate and $\mathrm{N}$-acetylcysteine have been considered, although the acute clinical efficacy of these agents has yet to be established. Sodium thiosulphate infusion (10\%) may prevent the toxic manifestations of SM, providing it is administered immediately after an exposure and no later than $30 \mathrm{~min}$ after exposure. ${ }^{103,104}$ There is no specific treatment for the delayed toxic effects and complications of SM in different target organs.

\section{Supportive}

Supportive care focuses on the prevention of infection and reduction of pain. Given the range of chronic health effects of SM, patients are best managed by multidisciplinary clinical teams of specialists. Financial, social, and cultural support together with health education to maintain a good lifestyle is of great importance. ${ }^{2}$

\section{Conclusions and recommendations}

The use of SM as an incapacitating warfare agent in the past century, particularly in WWI and the Iraq-Iran conflict, has proved its highly long-lasting toxic effects. This experience may ensure further use of the agent in future military and terrorist attacks. SM exerts its toxicity through a number of postulated pathogenic mechanisms including DNA alkylation, NAD depletion, and inactivation of glutathione. The eyes, skin, and respiratory system are the three major targets for the direct toxic effects of SM. When absorbed in large amounts, it can also damage rapidly proliferating cells of the bone marrow and cause severe suppression of the immune system, as well as other systemic toxicities such as neurological and digestive disorders. Even more important is a wide range of chronic health effects including chronic bronchitis, bronchiectasis, frequent bronchopneumonia, and pulmonary fibrosis, all of which tend to deteriorate in time. Severe dry skin, delayed keratitis, and pathogenic status of cell-mediated immunity with a subsequent increased risk of infections and even possible malignancies are also among the most distressing long-term consequences of SM intoxication. However, there are still major gaps in SM literature and further studies on humans exposed to the agent are required. Immunological and psychological dysfunctions, as well as the relationship between SM exposure, and carcinogenesis and teratogenesis are important fields that require further investigation. There is also a paucity of information regarding the medical management of acute and delayed toxic effects of SM poisoning, a subject that greatly challenges health care specialists.

It is hoped that by the advancement of the Organization for Prohibition of Chemical Weapons (OPCW), no CWA will be used in the future. However, chemical terrorism involving the use of SM remains a threat to human health globally. Thus, further studies on this subject are recommended. 


\section{Acknowledgements}

We greatly appreciate the financial support of the Iranian TWAS chapter at ISMO for preparation of this manuscript.

\section{Competing interests}

No competing interest was declared by any of the authors.

\section{Ethical approval}

Described in the text.

\section{Provenance and peer review}

Commissioned without payment; externally peer-reviewed.

\section{References}

1 Prentiss AM. Vesicant agents. Chemicals in Warfare: A Treatise on Chemical Warfare. McGraw-Hill: New York, USA, 1937, pp 177-300.

2 Balali-Mood M, Hefazi M. The pharmacology, toxicology, and medical treatment of sulphur mustard poisoning. Fundam Clin Pharmacol 2005;19:297-315.

3 United Nations Security Council. Report of the mission dispatched by the Secretary General to investigate allegations of the use of chemical weapons in the conflict between the Islamic Republic of Iran and Iraq. United Nations: New York, USA, 1988. April 25 1988. S/ 19823 and S/19823/Addendum 1.

4 Balali-Mood M, Hefazi M. Comparison of early and late toxic effects of sulfur mustard in Iranian veterans. Basic Clin Pharmacol Toxicol 2006;99:273-82.

5 Mandel M, Gibson WS. Clinical manifestations and treatment of gas poisoning. J Am Med Assoc 1917;69:1970-1.

6 Balali-Mood M, Hefazi M, Mahmoudi M, Jalali E, Attaran D, Maleki M, et al. Long-term complications of sulphur mustard poisoning in severely intoxicated Iranian veterans. Fundam Clin Pharmacol 2005;19:713-21.

7 Ghanei M, Fathi H, Mohammad MM, Aslani J, Nematizadeh F. Long-term respiratory disorders of claimers with subclinical exposure to chemical warfare agents. Inhal Toxicol 2004;16:491-5.

8 Brown EC. Pulmonary effects following chronic exposure to HS vapor. In: Medical Division Report No. 187. US Army Chemical Center: Washington, DC, USA, 1949, pp 01-31.

9 Nishimoto Y, Burrows B, Miyanishi M, Katsuta S, Shigenobu T, Kettel LJ. Chronic obstructive lung disease in Japanese poison gas workers. Am Rev Respir Dis 1970;102:173-9.

10 Hefazi M, Attaran D, Mahmoudi M, Balali-Mood M. Late respiratory complications of mustard gas poisoning in Iranian veterans. Inhal Toxicol 2005;17:587-92.

11 Hefazi M, Maleki M, Mahmoudi M, Tabatabaee A, Balali-Mood M. Delayed complications of sulfur mustard poisoning in the skin and the immune system of Iranian veterans $16-20$ years after exposure. Int J Dermatol 2006;45:1025-31.

12 Pickard HL. Ocular action of dichloroethyl sulfide (mustard gas). Am J Ophthalmol 1919;3:136.

13 Etezad-Razavi M, Mahmoudi M, Hefazi M, Balali-Mood M. Delayed ocular complications of mustard gas poisoning and the relationship with respiratory and cutaneous complications. Clin Experiment Ophthalmol 2006;34:342-6.

14 Balali-Mood M, Farhoodi M, Panjvani FK. Report of three fatal cases of war gas poisoning. In: Heyndrickx A (ed). Proceedings of the Second World Congress on New Compounds in Biological and Chemical Warfare. Rijksuniversiteit: Ghent, Belgium, 1986, pp 475-82.

15 Anslow WP, Houk CR. Systemic pharmacology and pathology of sulfur and nitrogen mustards. In: Anslow WP, Houk CR (eds).
Chemical Warfare Agents and Related Chemical Problems. National Defense Research Committee: Washington, DC, USA, 1946, pp 440-78.

16 World Health Organization. Health Aspects of Chemical and Biological Weapons. World Health Organization: Geneva, Switzerland, 1970.

17 McNamara BP, Owens EJ, Christensen MK, Vocci FJ, Ford DF, Rozimarek H. Toxicological Basis for Controlling Levels of Mustard in the Environment. EBSP-74030. US Army Armament Command. Biomedical Laboratory: Edgwood Arsenal, Aberdeen, USA, Aberdeen Providing Ground 1975.

18 Sidell FR, Hurst CG. Clinical considerations in mustard gas poisoning. In: Somani SM (ed). Chemical Warfare Agents. Academic Press: San Diego, USA, 1992, pp 156-94.

19 Balali-Mood M, Navaeian A. Clinical and paraclinical findings in 233 patients with sulfur mustard poisoning. In: Heyndrickx A (ed). Proceedings of the Second World Congress on New Compounds in Biological and Chemical Warfare. Rijksuniversiteit: Ghent, Belgium, 1986, pp 464-73.

20 Easton D, Peto J, Doll R. Cancers of the respiratory tract in mustard gas workers. Br J Ind Med 1988;45:652-9.

21 Walker IG. Interstrand bifunctional alkylation of DNA in mammalian cells treated with mustard gas. Can J Biochem 1971; 49:332-6.

22 Ball CR, Robert JJ. Estimation of interstrand DNA crosslinking resulting from mustard gas alkylation of HeLa cells. Chem Biol Interact 1972;4:2297-303.

23 Wheeler GP. Studies related to the mechanisms of cytotoxic alkylating agents: a review. Cancer Res 1962;22:651-88.

24 Rankin PW, Jacobson MK, Mitchell VR, Busbee DL. Reduction of nicotinamide adenine dinucleotide levels by ultimate carcinogens in human lymphocytes. Cancer Res 1980;40: 1803-1807.

25 Eklow L, Moldeus P, Orrenius S. Oxidation of glutathione during hydroperoxide metabolism: a study using isolated hepatocytes and glutathione reductase inhibitor 1, 3-bis(2-chloroethyl)-1nitrosurea. Eur J Biochem 2004;138:459-63.

26 Cullumbine H. Medical aspects of mustard gas poisoning. Nature 1947;159:151-3.

27 Langenberg JP, van der Schans GP, Spruit HE, Kuijpers WC, MarsGronendijk RH, van Dijk-Knijenburg HC. Toxicokinetics of sulphur mustard and its DNA-adducts. Drug Chem Toxicol 1998;21 (Suppl): 131-47.

28 Chilcott RP, Jenner J, Carrick W, Hotchkiss SA, Rice P. Human skin absorption of bis-2-(chloroethyl)sulphide (sulphur mustard) in vitro. J Appl Toxicol 2000;20:349-55.

29 Davison C, Rozman RS, Smith PK. Metabolism of bis-betachloroethylsulfide (sulphur mustard gas). Biochem Pharmacol 1961;7:65-74

30 Kehe K, Szinicz L. Medical aspects of sulphur mustard poisoning. Toxicology 2005;214:198-209.

31 Clemedson CJ, Kristoffersson H, Sörbo B, Ullberg S. Whole body autoradiographic studies of the distribution of sulphur 35-labelled mustard gas in mice. Acta Radiol Ther 1963;1: 314-320.

32 Drasch G, Kretschmer G, Kauert L, von Meyer L. Concentration of mustard gas [bis(2-chloroethyl)sulfide] in the tissues of a victim of a vesicant exposure. J Forensic Sci 1987;32:1788-93.

33 Roberts JJ, Warwick GP. Studies of the mode of action of alkylating agents. VI. The metabolism of bis-2-chlorethylsulphide (mustard gas) and related compounds. Biochem Pharmacol 1963;12:1329-34.

34 Sasser LB, Cushing JA, Dacre JC. Two-generation reproduction study of sulfur mustard in rats. Reprod Toxicol 1996;10:311-19.

35 Pechuta CM, Rall DP. Relationship of mustard agent and Lewisite exposure to carcinogenesis. In: Pechuta CM, Rall DP (eds). Veterans at Risk, the Health Effects of Mustard Gas and Lewisite. National Academy Press: Washington DC, USA, 1993, pp 81-111. 
36 Wada S, Nishimoto Y, Miyanishi M, Kambe S, Miller RW. Mustard gas: a cause of respiratory neoplasia in man. Lancet 1968;2:1161-1163.

37 Manning KP, Kegg DCG, Stell PM, Doll R. Cancer of the larynx and other occupational hazards of mustard gas workers. Clin Otolaryngol 1981;6:165-70.

38 Balali-Mood M. Evaluation of late toxic effects of sulfur mustard poisoning in 1428 Iranian veterans. The Seminar on Late Complications of Chemical Warfare Agents in Iranian Veterans. Veteran Foundation: Tehran, Iran, 1992, pp 15-37.

39 Inada S, Hiragun K, Seo K, Yamura T. Multiple Bowen's disease observed in former workers of a poison gas factory in Japan with special references to mustard gas exposure. J Dermatol 1978;5: 49-60.

40 Graef I, Karnofsky DA, Jaeger V, Krichesky B, Smith HW. The clinical and pathologic effects of the nitrogen and sulfur mustards in laboratory animals. Am J Pathol 1948;24:01-47.

41 Giraud $\mathrm{H}$. The first symptoms of intoxication from mustard gas. J Med Chir Prat 1917;88:890-4.

42 Helm UK, Balali-Mood M. Cutaneous lesions produced by sulfur mustard. The First International Medical Congress on Chemical Warfare Agents in Iran. Mashhad University of Medical Sciences:Mashhad, Iran; 13-16 June 1988. No. 90.

43 Papirmeister B, Feister AJ, Robinson SI. Medical defense against mustard gas: toxic mechanisms and pharmacological implications. CRC Press: Boca Raton, USA, 1991.

44 Canelli AF. Contrbuto alla conoscenza dell' intossicazione acuta da 'Yperite' ed in particolare del suo reperto anatomo-patologico. Rivista Ospedaliera Italiana 1918;8:2-7.

45 Thomsen AB, Erkisen Y, Smidt-Nielsen K. Chronic neuropathic symptoms after exposure to mustard gas: a long-term investigation. J Am Acad Dermatol 1988;39:187-90.

46 Willems JL. Clinical management of mustard gas casualties. Ann Med Mil Belg 1989;3:S1-61.

47 Balali-Mood M, Tabarestani M, Farhoodi M, Panjvani FK. Study of clinical and laboratory findings of sulfur mustard in 329 war victims. Med J IR Iran 1991;34:7-15.

48 Tabarestani M, Balali-Mood M, Farhoodi M. Hematological findings of sulfur mustard poisoning in Iranian combatants. Med J IR Iran 1990;4:190.

49 Mahmoudi M, Hefazi M, Rastin M, Balali-Mood M. Long-term hematological and immunological complications of sulfur mustard poisoning in Iranian veterans. Int Immunopharmacol 2005;5:1479-85.

50 Tabarestani M, Farhoudi M, Balali-Mood M. Stem cell and erythroid precursors disorders in three patients with sulfur mustard poisoning. The First International Medical Congress on Chemical Warfare Agents in Iran.. Mashhad University of Medical Sciences: Mashhad, Iran; 13-16 June 1988. No. 10.

51 Krumbhaar EB, Krumbhaar HD. The blood and bone marrow in yellow cross gas (mustard gas) poisoning. J Med Res 1919;40: 497-506.

52 Dayhimi I, Bahar K, Eliasy H. The effect of sulfur mustard gas (SMG) on the immune system. The First International Medical Congress on Chemical Warfare Agents in Iran. Mashhad University of Medical Sciences: Mashhad, Iran; 13-16 June 1988. No. 12.

53 Zandieh T, Marzaban S, Tarabadi F, Ansari H. Defects of cellmediated immunity in mustard gas injury after years (Abstract). Scan I Immunol 1990;32:423.

54 Ghotbi L, Hassan Z. The immunostatus of natural killer cells in people exposed to sulphur mustard. Int Immunopharmacol 2002;2:981-5.

55 Dacre JC, Goldman M. Toxicology and pharmacology of the chemical warfare agent sulphur mustard. Pharmacol Rev 1996;48:289-326.

56 Aghanouri R, Ghanei M, Aslani J, Keivani-Amine H, Rastegar F, Karkhane A. Fibrogenic cytokine levels in bronchoalveolar lavage aspirates 15 years after exposure to sulfur mustard. Am J Physiol Lung Cell Mol Physiol 2004;287:1160-4.
57 WHO. Health Aspects of Chemical and Biological warfare Agents. World Health Organization: Geneva, Switzerland, December 2003.

58 Heyndrickx A. Analytical methods for detection and determination of sulphur mustard in environmental and biological samples. In: Heyndrickx B (ed). Proceedings of the Second World Congress on New Compounds in Biological and Chemical Warfare. Rijksuniversiteit: Ghent, Belgium, 1986, pp 112-28.

59 Noort D, Benschop HP, Black RM. Biomonitoring of exposure to chemical warfare agents: a review. Toxicol Appl Pharmacol 2002;184:116-26.

60 Fidder A, Moes GWH, Scheffer AG, van der Sohans GP, Baan RA, de Jong LP, et al. Synthesis, characterization, and quantification of the major adducts formed between sulfur mustard and DNA of calf thymus and human blood. Chem Res Toxicol 2005; 7:199-204.

61 Fidder A, Noort D, De Jong LPA, Benschop HP, Hulst AJ. N7-(2hydroxyethylthioethyl)-guanine: a novel urinary metabolite following exposure to sulfur mustard. Arch Toxicol 1996; 70:854-5

62 van der Schans GP, Scheffer AG, Mars-Groenendijk RH, Fidder A Benschop HP, Baan RA. Immunochemical detection of adducts of sulfur mustard to DNA of calf thymus and human white blood cells. Chem Res Toxicol 1994;7:408-13.

63 Benschop HP, van der Schans GP, Noort D, Fidder A, MarsGroenendijk RH, De Jong LPA. Verification of exposure to sulfur mustard in two casualties of the Iran-Iraq conflict. J Anal Toxicol 1997;21:249-51.

64 Black RM, Brewsterk K, Clarke RJ, Hambrook JL, Harrison JM, Howells DJ. Biological fate of sulfur mustard, 1,1'-thiobis(2chloroethane): isolation and identification of urinary metabolites following intraperitoneal administration to rat. Xenobiotica 1992;22:405-18.

65 Black RM, Read RW. Biological fate of sulfur mustard, 1, $1^{\prime}$ thiobis(2-chloroethane): identification of X-lyasemetabolites and hydrolysis products in human urine. Xenobiotica 1995;25: 167-73.

66 Wils ERJ, Hulst AJ, De Jong AL, Verwij A, Boter HL. Analysis of thiodiglycol in urine of victims of an alleged attack with mustard gas. I Anal Toxicol 1985;9:254-7.

67 Wils ERJ, Hulst AJ, van Laar J. Analysis of thiodiglycol in urine of victims of an alleged attack with mustard gas, part II. J Anal Toxicol 1988;12:15-19.

68 Black RM, Read RW. Detection of trace levels of thiodiglycol in blood, plasma, and urine using gas chromatography electron capture negative ion chemical ionization mass spectrometry. I Chromatogr 1988;449:261-70.

69 Black RM, Read RW. Improved methodology for the detection and quantitation of urinary metabolites of sulfur mustard using gas chromatography tandem mass spectrometry. J Chromatogr Biomed Appl 1995;665:97-105.

70 Sulzberger MB, Katz JH. The absence of skin irritants in the contents of vesicles. US Navy Med Bull 1943;43:1258-62.

71 Black RM, Clarke RJ, Harrison JM, Read RW. Biological fate of sulphur mustard: identification of valine and histidine adducts in hemoglobin from casualties of sulphur mustard poisoning. Xenobiotica 1997;27:499-512.

72 Crathorn AR, Robert JJ. Mechanism of cytotoxic action of alkylating agents in mammalian cells and evidence for the removal of alkylated groups from deoxyribonucleic acid. Nature 1966;211:150-3.

73 Maynard RL, Meredith TJ, Marrs TC, Vale JA. Management of chemical warfare injuries (Letter). Lancet 1991;337:122.

74 World Health Organization. Chemical agents. In: Perry-Robinson JP (ed). Public Health Response to Biological and Chemical Weapons, 2nd edn. World Health Organization: Geneva, Switzerland, 2004, pp 164-701.

75 Bagheri MH, Hosseini SK, Mostafavi SH, Alavi SA. Highresolution CT in chronic pulmonary changes after mustard gas exposure. Acta Radiol 2003;44:241-5. 
76 Bijani KH, Moghadamnia AA. Long-term effects of chemical weapons on respiratory tract in the Iran-Iraq war victims living in Babol (North of Iran). Ecotoxicol Environ Saf 2002;53:422-4.

77 Emad A, Rezaian GR. The diversity of effects of sulfur mustard gas inhalation on respiratory system 10 years after a single heavy exposure: analysis of 197 cases. Chest 1997;112:734-8.

78 Balali-Mood M, Hefazi M, Mahmoudi M, Jalali E, Attaran D, Maleki M, et al. Evaluation of delayed toxic effects of sulfur mustard poisoning in severely intoxicated Iranian veterans. $J$ Med CB R Def 2005;3. Available at http: //www.J Med Chem Def. org/issue_0301/Balali-Mood_0405.html.

79 Afshinniaz F, Ghanei M. Relationship of the Chronic Respiratory Symptoms with Spirometric and Laboratory Parameters (Dissertation). Isfahan University of Medical Sciences: Isfahan, Iran, 1995.

80 Somani SM, Babu SR. Toxicodynamics of sulfur mustard. Int J Clin Pharmacol Ther Toxicol 1989;27:419-35.

81 Hosseini K. Development of bronchiectasis, a late sequel of mustard gas exposure. Iran J Med Sci 1998;23:81-4.

82 Ghanei M, Akhlaghpoor A, Mohammad MM, Aslani J. Tracheobronchial stenosis following mustard gas inhalation. Inhal Toxicol 2004;16:845-9.

83 Aslani J. Late respiratory complications of sulfur mustard. In: Cheraghali AM (ed). Prevention and Treatment of Complications of Chemical Warfare Agents. Chemical Warfare Research Center: Tehran, Iran, 2000, pp 76-9.

84 Samieepour M, Ghanei M. Evaluation of the Relationship Between Cytotoxic and Pathologic Findings in Chemical Warfare-Injured Veterans. (Dissertation). Fatemieh University of Medical Sciences: Ghom, Iran, 2001.

85 Sohrabpour H. Evaluation of Late Toxic Effects of Sulfur Mustard Poisoning with Electron Microscopy of Lung Biopsies. (Dissertation). Shaheed Beheshti University of Medical Sciences: Tehran, Iran, 1992.

86 Chiesman WE. Diagnosis and treatment of lesions due to svesicants. Br Med J 1944;2:109-12.

87 Fekri AR, Janghorbani M. Late cutaneous complications in Iranian veterans. The Seminar on Late Complications of Chemical Warfare Agents in Iranian Veterans. Veteran Foundation: Tehran, Iran, 1992, pp 57-89.

88 Khehr NW. Late manifestations in former mustard gas workers with special consideration of the cutaneous findings. Zeitschrift fur Hautkrankheiten 1984;59:1161-70.

89 Blodi FC. Mustard gas keratopathy. Int Ophthalmol Clin 1971;2:113.

90 English F, Benett Y. The challenge of mustard gas keratopathy. Med I Austr 1990;152:55-6.
91 Hughes WF. Mustard gas injuries to the eyes. Arch Ophthalmol 1942;27:582-601.

92 Pleyer U, Sherif Z, Baatz H, Hartmann C. Delayed mustard gas keratopathy: clinical findings and confocal microscopy. Am J Ophthalmol 1999;128:506-7.

93 Javadi MA, Kazemi-Moghadam M. Ocular effects of sulfur mustard poisoning. In: Cheraghali AM (ed). Prevention and Treatment of Complications of Chemical Warfare Agents. Chemical Warfare Research Center: Tehran, Iran, 2000, pp 82-101.

94 Solberg Y, Alcalay M, Belkin M. Ocular injury by mustard gas. Surv Ophthalmol 1997;41:461-6.

95 Vedder EB. The Medical Aspects of Chemical Warfare. Williams and Wilkins: Baltimore, USA, 1925

96 Balali-Mood M. First report of delayed toxic effects of Yperite poisoning in Iranian fighters. In: Heyndrickx B (ed). Proceedings of the Second World Congress on New Compounds in Biological and Chemical Warfare. Rijksuniversiteit: Ghent, Belgium, 1986, pp 489-95.

97 Tabatabaee SM. Study of psychiatric complications of poisoning with chemical warfare agents. The First International Medical Congress on Chemical Warfare Agents in Iran. Mashhad University of Medical Sciences: Mashhad, Iran; 13-16 June 1988. No. 66.

98 Hashemian F, Khoshnood K, Desai MM, Falahati F, Kasl S, Southwick S. Anxiety, depression and posttraumatic stress in Iranian survivors of chemical warfare. JAMA 2006;296:560-6.

99 Ludlum DB, Kent S, Mehta JR. Formation of $\mathrm{O}_{6}$-ethylthioethylguanine in DNA by reaction with the sulfur mustard, chloroethyl sulfide, and its apparent lack of repair by $\mathrm{O}_{6}$ alkylguanine-DNA alkyltransferase. Carcinogenesis 1986;7:1203-6.

100 Takeshima Y, Inai K, Bennett WP, Metcalf RA, Welsh JA, Yonehara S, et al. p53 mutations in lung cancers from Japanese mustard gas workers. Carcinogenesis 1994;15:2075-9.

101 Yanagida J, Hozawa S, Ishioka S, Maeda H, Takahashi K, Oyama $\mathrm{T}$, et al. Somatic mutation in peripheral lymphocytes of former workers at the Okunojima poison gas factory. Jpn J Cancer Res 1988;79:1276-83.

102 Azizi F, Keshavarz A, Roshanzamir F, Nafarabadi M. Reproductive function in men following exposure to chemical warfare with sulfur mustard. Med War 1995;11:34-44

103 Callaway S, Pearce KA. Protection against systemic poisoning by mustard gas, di(2-chloroethyl) sulphide, by sodium thiosulphate and thiocit in the albino rat. Br J Pharmacol 1958;13:395-8.

104 Connors TA, Jeney A, Jones M. Reduction of the toxicity of 'radiomimetic' alkylating agents in rats by thiol pretreatment. The mechanism of the protective action of thiosulfate. Biochem Pharmacol 1964;13:1545-50. 